\title{
The epidemiology of fractures in England
}

L J Donaldson, I P Reckless, S Scholes, J S Mindell and N J Shelton

J. Epidemiol. Community Health 2008;62;174-180

doi:10.1136/jech.2006.056622

Updated information and services can be found at:

http://jech.bmj.com/cgi/content/full/62/2/174

These include:

References This article cites 19 articles, 7 of which can be accessed free at: http://jech.bmj.com/cgi/content/full/62/2/174\#BIBL

Rapid responses You can respond to this article at:

http://jech.bmj.com/cgi/eletter-submit/62/2/174

Email alerting Receive free email alerts when new articles cite this article - sign up in the box at service the top right corner of the article

Notes

To order reprints of this article go to:

http://journals.bmj.com/cgi/reprintform

To subscribe to Journal of Epidemiology and Community Health go to:

http://journals.bmj.com/subscriptions/ 


\title{
The epidemiology of fractures in England
}

\author{
L J Donaldson, ${ }^{1}$ I P Reckless, ${ }^{1}$ S Scholes, ${ }^{2}$ J S Mindell, ${ }^{3}$ N J Shelton ${ }^{3}$
}

- Additional details of household and individual response rates for the general population and minority ethnic group samples are published online only at http://jech.bmj. com/content/vol62/issue2

${ }^{1}$ Department of Health, London, UK; ${ }^{2}$ National Centre for Social Research, London, UK;

${ }^{3}$ Department of Epidemiology and Public Health, University College London, London, UK

Correspondence to: L J Donaldson, Department of Health, London; liam. donaldson@dh.gsi.gov.uk

Accepted 2 March 2007

\author{
ABSTRACT \\ Introduction: Fractures are a considerable public health \\ burden in the United Kingdom but information on their \\ epidemiology is limited.
}

Objective: This study aims to estimate the true annual incidence and lifetime prevalence of fractures in England, within both the general population and specific groups, using a self-report methodology.

Methods: A self-report survey of a nationally representative general population sample of 45293 individuals in England, plus a special boost sample of 10111 drawn from the ethnic minority population.

Results: The calculated fracture incidence is 3.6 fractures per 100 people per year. Lifetime fracture prevalence exceeds $50 \%$ in middle-aged men, and $40 \%$ in women over the age of 75 years. Fractures occur with reduced frequency in the non-white population: this effect is seen across most black and minority ethnic groups.

Conclusions: This study suggests that fractures in England may be more common than previously estimated, with an overall annual fracture incidence of $3.6 \%$. Agestandardised lifetime fracture prevalence is estimated to be $38.2 \%$. Fractures are more commonplace in the white population.

Fractures, mostly arising from injury, are an important public health burden. The combined annual health and social care costs of hip fractures alone were estimated at $£ 726$ million in the United Kingdom in $2000 .{ }^{1}$

The poverty of basic epidemiological data on the incidence of fractures and their distribution in the population in England was identified over 15 years ago. ${ }^{2}$ At that time, the 'gold standard' with which most epidemiological studies in the United Kingdom compared their results was a 1950s population-based study. ${ }^{3}$ Improvements in the quality and availability of information on fractures since then have been modest. Meanwhile, potential risk factors for fracture in the population, including recreational habits, ethnicity and occupation, have changed.

Typically, a patient with a fracture in England will first attend a National Health Service emergency department. After diagnosis and initial management, many will then be referred on to a fracture clinic for review by a specialist orthopaedic team.

There are a number of different ways in which the incidence of fracture in a population can be estimated from healthcare records. Examination of Hospital Episode Statistics for 2004/2005 showed 338941 finished consultant episodes with a diagnosis of fracture in England, but this includes only those patients admitted to hospital, or undergoing an operative procedure. In the United Kingdom literature, data have also been collected through the use of fracture clinic, ${ }^{2}$ emergency department, ${ }^{45}$ and primary care records. ${ }^{6}$

There are alternative pathways for a patient with a fracture, which means that their fracture would not be ascertained through these points of contact with the healthcare system. Moreover, there are a number of potential sources of error in the data that are collected (Box 1 and Box 2).

Our study aims to provide new information on the epidemiology of fractures in the whole country, drawing on self-reporting by a nationally representative random sample of the general population, rather than hospital records. Although this method of ascertainment itself has limitations, ${ }^{7}$ it avoids many of the sources of error inherent in previous studies and is likely to give an estimate of the frequency of fractures within the population that is closer to their true incidence.

\section{METHODS}

\section{Data sources}

The Health Survey for England (HSE) is a series of annual surveys of the health of people in England, commissioned by the Department of Health. Each year, a sample is designed to provide a representative cross-section of the population of England living in private households. In some years, the size of this general population sample is reduced in order to accommodate a "boost sample" to allow for focused examination of the health of specific groups within society. In 2002-2004, the overall HSE sample size each year was over 18000 individuals.

Data are collected through face-to-face interviews. The detailed methodology used by the HSE is described in detail elsewhere. ${ }^{8-10}$ A module on fractures was included in the HSE for the first time in 2002. Survey participants for 2002 and 2003, and those in the general population sample for 2004 were asked to recall the total number of episodes of fracture injury sustained in the past 12 months. When an episode was recalled, participants were asked to provide detailed information on the number and types of bones fractured. A maximum of three separate fracture episodes per participant have been included. The annual fracture incidence rate is defined as the number of people per 100 respondents reporting one or more fractures in the 12 months preceding interview.

In addition, informants were also asked whether they had ever fractured a bone, other than in the past 12 months. In order to estimate the lifetime prevalence of fracture, the sum of individuals reporting one or more fractures in the past 12 months and those who reported fracture other than in the past 12 months was calculated. Data have thus been collected on both the annual incidence and lifetime prevalence of fracture. 
Box 1 Patient pathways that may not be captured by data drawn from emergency departments and fracture clinics

- Injuries do not result in contact with health services

- Patients admitted to hospital for ongoing management of the fracture and any concurrent medical problems

- Patients managed directly from primary care

- Patients who die as a result of the trauma in which fractures are sustained

When participants had experienced a fracture in the previous 12 months, they were invited to identify the location of the fracture with the aid of one or more diagrams of a skeleton. This categorisation divided fractures into broad groups. Such categorisation masks the contribution of specific fracture sites but pools the number of fractures occurring in a given group to permit meaningful comparison between groups. As some respondents had broken more than one bone in an episode, or had experienced multiple fracture episodes during the course of a year (table 1), the sum of site-specific incidence rates is greater than the headline incidence rate.

The 2002 HSE sample was stratified to focus upon young people (aged under 25 years) and the mothers of infants. Information pertaining to individuals falling outside these two groups was weighted in order to account for their reduced representation in the sample. In all years, a maximum of two children per household were included (selected at random) to limit the burden placed on households with a larger number of children. Weighting was then applied to take account of the underrepresentation of children in such households. ${ }^{8-10}$

In 2004, the general population sample was reduced in size by half in order to focus on the health of ethnic minorities. Fewer questions on fracture were asked of the minority ethnic boost participants, as the main purpose of the 2004 boost sample was to assess cardiovascular disease in the ethnic minority population. For example, questions on the site of fracture were omitted, because of time constraints in the interview.

In the HSE, children are defined as $0-15$ years and adults as 16 years and over; there is no upper age limit. Details of household and individual response rates for the general population and minority ethnic group samples are published in an appendix (table w1, table w2) available online only. It should be noted that the "general population" sample was selected to be nationally representative and therefore includes members of the whole population of England, regardless of minority ethnic

\section{Box 2 Potential errors with data that are captured} pertaining to fracture epidemiology

- Difficulties matching numerator with denominator (hospital catchment populations unreliable)

- Underestimation of fracture incidence (for example, a clinical diagnosis of rib fracture may not be coded as a definite fracture)

- Overestimation of fracture incidence (old injuries may be counted as new fractures, for example, old vertebral fractures in elderly patients presenting with back pain)

- Errors in clinical coding

- Missed clinical diagnoses

group. It should not be interpreted as "the remainder of the population", excluding those from the seven minority ethnic groups included in the minority ethnic boost. The age distribution of the HSE 2002-2004 respondents analysed in this study is compared with the 2001 Census, by sex, in the online appendix (table w3).

\section{Analyses}

The HSE uses a clustered, stratified multistage sample design; 95\% confidence intervals (CI) are calculated using the STATA software package (STATA Corp., College Station, Texas, USA) to account for this complex design..$^{8-10}$

Two sets of analyses were conducted. The first established incidence and lifetime prevalence rates for fracture by age, sex, social class (current or former manual and non-manual occupation, defined according to the Registrar General's classification) and crude ethnicity (white, including Irish, versus non-white) for the general population in England. The second set compared incidence and lifetime prevalence rates for fractures across seven ethnic groups. The data sources for these analyses are described in table 1.

Age standardisation facilitated comparison between subgroups in the sample. The direct standardisation method was used, with the 2001 Census population for England as the reference population. ${ }^{11}$

\section{RESULTS}

\section{Incidence in the general population}

The age-standardised annual fracture incidence was 3.6 per 100 people of all ages ( $95 \%$ CI 3.4 to 3.8). The incidence of fractures was significantly higher in men (4.1 per $100,95 \%$ CI 3.8 to 4.4 )

Table 1 Number of participants and recent fractures included in the analyses, and the mean age of these participants

\begin{tabular}{|c|c|c|c|c|c|c|c|c|c|}
\hline \multirow[b]{2}{*}{ Year } & \multirow[b]{2}{*}{ Group } & \multicolumn{3}{|l|}{ Sex } & \multicolumn{2}{|c|}{ Mean age (years) } & \multirow{2}{*}{$\begin{array}{l}\text { No. respondents } \\
\text { reporting } \geqslant 1 \\
\text { fracture in past } \\
\text { year }\end{array}$} & \multirow{2}{*}{$\begin{array}{l}\text { No. respondents } \\
\text { experiencing } \\
\text { multiple fracture } \\
\text { episodes in } \\
\text { past year }\end{array}$} & \multirow{2}{*}{$\begin{array}{l}\text { No. respondents } \\
\text { who broke } \geqslant 1 \\
\text { bone in an } \\
\text { episode }\end{array}$} \\
\hline & & Male & Female & All & Unweighted & $\begin{array}{l}\text { Weighted by } \\
\text { interview } \\
\text { weight }\end{array}$ & & & \\
\hline 2002 & General population & 8642 & 9751 & 18393 & 25.6 & 38.3 & 710 & 84 & 43 \\
\hline 2003 & General population & 8458 & 10088 & 18546 & 40.1 & 40.1 & 613 & 42 & 44 \\
\hline 2004 & General population & 3728 & 4626 & 8354 & 41.1 & 41.1 & $308 *$ & 21 & 19 \\
\hline 2004 & Ethnic minority boost & 4748 & 5363 & 10111 & 29.6 & 31.4 & 207 & Not collected & Not collected \\
\hline Analysis 1 & $\begin{array}{l}\text { General population } \\
\text { 2002-2004 }\end{array}$ & 20828 & 24465 & 45293 & 34.4 & 39.1 & $1631^{*}$ & 147 & 106 \\
\hline Analysis 2 & $\begin{array}{l}\text { General population } \\
2004 \text { and ethnic } \\
\text { minority boost } 2004\end{array}$ & 8476 & 9989 & 18465 & 34.8 & 37.9 & $514^{*}$ & Not collected & Not collected \\
\hline
\end{tabular}

\footnotetext{
${ }^{*} \mathrm{~A}$ total of 26 of these individuals provided incomplete information on fracture site and are therefore excluded from any site-specific analyses.
} 
Table 2 Annual fracture incidence among men by age and crude ethnicity

\begin{tabular}{|c|c|c|c|c|}
\hline \multirow[b]{3}{*}{ Age (years) } & \multicolumn{4}{|c|}{ Annual fracture incidence per 100 men $(95 \% \mathrm{Cl})$} \\
\hline & \multicolumn{2}{|l|}{ White } & \multicolumn{2}{|c|}{ Non-white } \\
\hline & \multicolumn{2}{|c|}{ Unweighted base size } & \multicolumn{2}{|c|}{ Unweighted base size } \\
\hline $0-14$ & 5504 & $4.9(4.3$ to 5.5$)$ & 876 & 2.8 (1.6 to 4.0$)$ \\
\hline $15-34$ & 4436 & $6.8(5.9$ to 7.7$)$ & 660 & 3.4 (1.6 to 5.2$)$ \\
\hline $35-54$ & 4177 & $3.0(2.3$ to 3.6$)$ & 367 & 3.5 (1.2 to 5.8$)$ \\
\hline $55-74$ & 3506 & 2.6 (1.9 to 3.3$)$ & 157 & $1.6(0.0$ to 4.8$)$ \\
\hline $75+$ & 1070 & 2.3 (1.1 to 3.5$)$ & 25 & $0.0(0.0$ to 0.0$)$ \\
\hline Overall & 18693 & $4.3(3.9$ to 4.6$)$ & 2085 & 2.8 (1.7 to 3.8$)$ \\
\hline
\end{tabular}
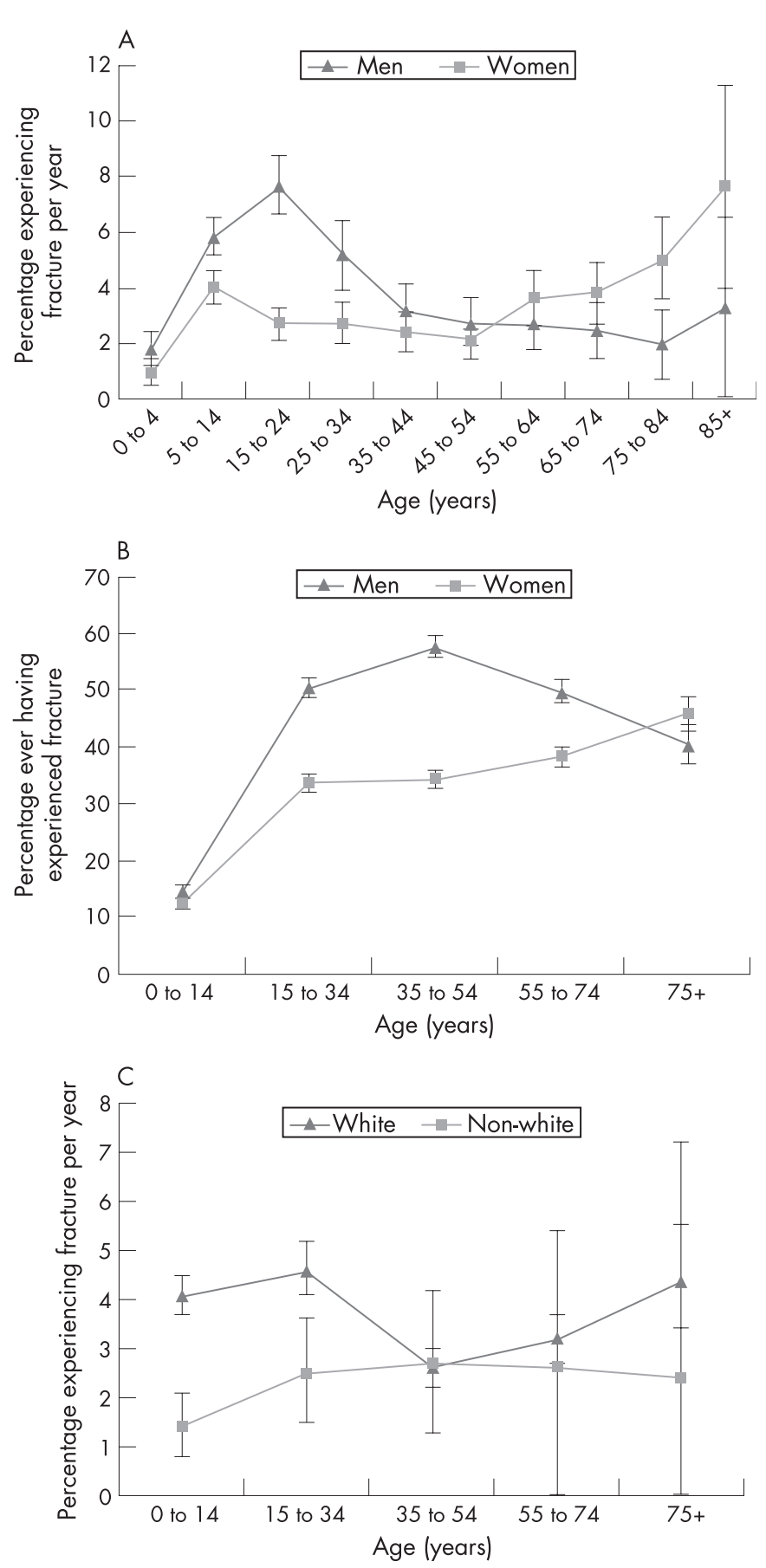

Figure 1 Annual fracture incidence and lifetime fracture prevalence per 100 people, by age, sex and crude ethnicity, English general population 2002-2004. than in women (3.1 per 100, 95\% CI 2.8 to 3.4 ). For males, fracture incidence increased rapidly with age from 1.8 per 100 in boys aged zero to four years (95\% CI 1.2 to 2.4 ), to 7.7 per 100 in men aged 15-24 years (95\% CI 6.7 to 8.7 ), after which it declined until the age of 85 years and over (fig 1A).

For females, the initial peak in fracture incidence was earlier (age five to 14 years) and less pronounced (4.0 per 100, 95\% CI 3.4 to 4.6). A larger and sustained rise in the incidence of fracture occurred among women over 55 years, however, reaching a peak incidence of 7.6 fractures per 100 women (95\% CI 4.0 to 11.3). The peak incidence of fracture in males and females was thus similar in magnitude but occurred at different ends of the age spectrum.

Fractures most commonly involved the feet and hands, followed by the long bones and the trunk. Fractures involving the skull and other bones in the head were comparatively rare (fig 2).

The male to female ratio in fracture incidence altered markedly between those under 55 years and those over 55 years (with a substantial male fracture preponderance being replaced by a substantial female preponderance; fig 3). This effect was seen across all fracture categories examined apart from head fractures, and was most marked in fractures of the trunk (including vertebral fractures) and long bones (including hip fractures).

A higher proportion of those aged 16 years and over involved in manual occupations reported fracturing a bone in the previous 12 months, 4.0 per 100 (95\% CI 3.5 to 4.4) compared with 3.0 per 100 (95\% CI 2.7 to 3.4) among those in the nonmanual group.

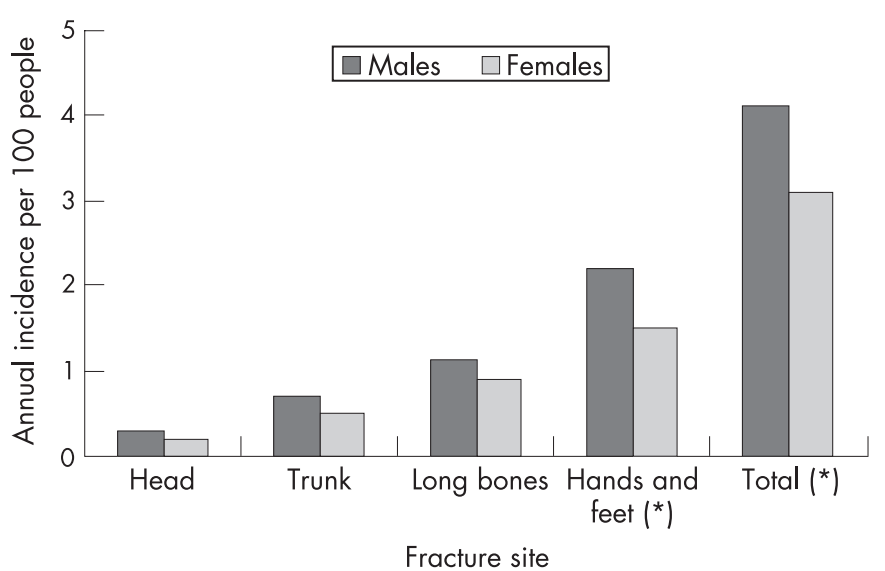

Figure 2 Annual fracture incidence by sex and site, English general population, all ages, 2002-2004.

${ }^{*}$ Sex difference significant at a $95 \%$ confidence level. 
Table 3 Fracture prevalence by age and crude ethnicity

\begin{tabular}{|c|c|c|c|c|}
\hline \multirow[b]{3}{*}{ Age (years) } & \multicolumn{4}{|c|}{ Fracture prevalence per 100 people $(95 \% \mathrm{Cl})$} \\
\hline & \multicolumn{2}{|l|}{ White } & \multicolumn{2}{|c|}{ Non-white } \\
\hline & \multicolumn{2}{|c|}{ Unweighted base size } & \multicolumn{2}{|c|}{ Unweighted base size } \\
\hline $0-14$ & 10856 & $14.4(13.7$ to 15.1$)$ & 1711 & $8.1(6.5$ to 9.4$)$ \\
\hline $15-34$ & 9822 & $44.3(43.0$ to 45.5$)$ & 1513 & $24.1(21.5$ to 26.7$)$ \\
\hline $35-54$ & 9513 & $46.8(45.5$ to 48.0$)$ & 874 & $26.2(22.6$ to 29.7$)$ \\
\hline $55-74$ & 7741 & $44.2(42.8$ to 45.6$)$ & 315 & 25.5 (18.8 to 32.2$)$ \\
\hline $75+$ & 2804 & $44.4(42.1$ to 46.6$)$ & 39 & $25.7(1.9$ to 49.5$)$ \\
\hline Overall & 40736 & $39.3(38.7$ to 40.0$)$ & 4452 & $22.0(19.4$ to 24.6$)$ \\
\hline
\end{tabular}

\section{Prevalence in the general population}

For people of all ages, age-standardised fracture prevalence was 38.2 per 100 people ( $95 \%$ CI 37.6 to 38.8), and it was higher in males (44.7 per 100, 95\% CI 43.8 to 45.6 ) than in females ( 32.0 per $100,95 \%$ CI 31.3 to 32.8 ). Males had a significantly higher fracture prevalence than females in every age group except the over 75s, in which the trend was towards an increased prevalence in women (fig 1B). Fracture prevalence was higher in manual than non-manual occupational groups, both in those aged $16-34$ years ( 47.1 per $100,95 \%$ CI 45.2 to 49.0 versus 40.8 per $100,95 \%$ CI 39.1 to 42.5 ) and in those aged $35-54$ years (47.8 per 100 , $95 \%$ CI 45.9 to 49.8 versus 43.5 per $100,95 \%$ CI 41.9 to 45.1$)$.

\section{Fracture rates by ethnicity}

In the 2002-2004 general population analysis, non-white males had a lower incidence of fracture than white males, largely because of differences among younger males (less than 35 years old) and older men (over 75 years of age; table 2, fig 1C). Nonwhite girls under 15 years of age also had a lower incidence of fracture than their white counterparts (0.4 per 100, 95\% CI 0.0 to 0.9 versus 3.3 per $100,95 \%$ CI 2.8 to 3.9$)$.

The lifetime prevalence of fractures was significantly higher in the white than the non-white ethnic group (39.3 per 100, $95 \%$ CI 38.7 to 40.0 versus 22.0 per $100,95 \%$ CI 19.4 to 24.6 ).

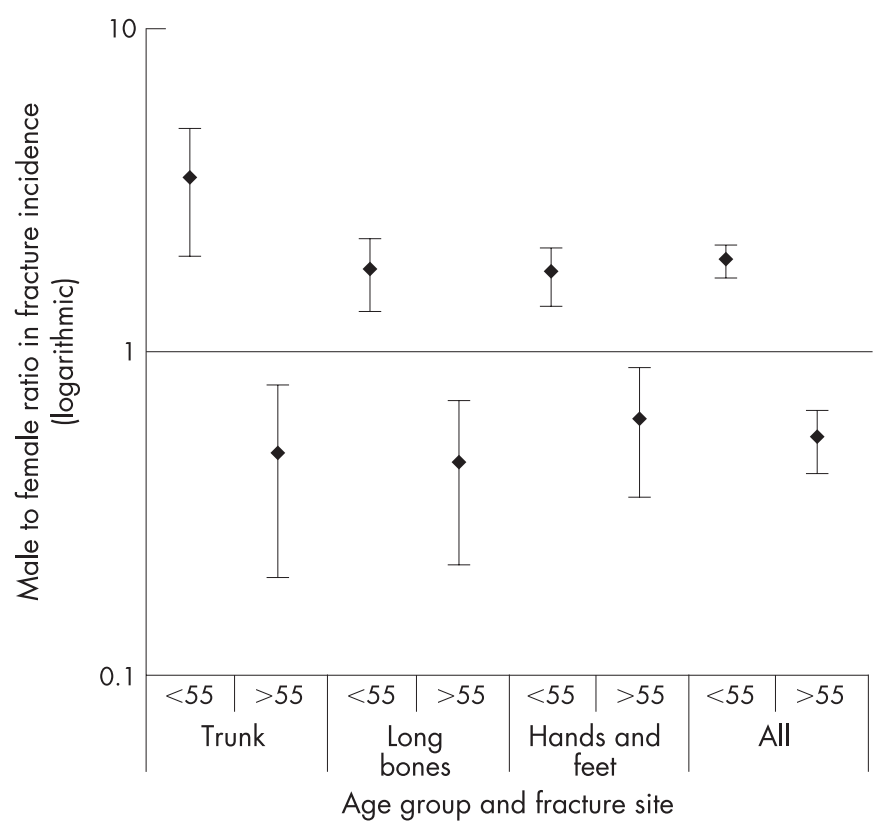

Figure 3 Male to female fracture incidence ratios (age-standardised) by age group and fracture site, English general population, 2002-2004.
This was seen across all age groups until the age of 75 years, at which point this difference lost statistical significance (because of the small non-white elderly sample size; table 3 ).

The second analysis, comparing data from the ethnic minority boost sample of HSE 2004 with data from the general population sample from the same year, was more revealing. Among males, age-standardised fracture incidence rates were significantly lower in all ethnic minority groups examined, apart from the Irish and Pakistani population. In females, in whom confidence intervals were generally wider, incidence rates were significantly lower in black African, Pakistani and Bangladeshi populations (fig 4A). When age-standardised fracture prevalence was examined, the results were more striking. Each ethnic group examined, other than the Irish, had significantly lower fracture prevalence than the general HSE 2004 sample, in both males and females (fig 4B).

\section{DISCUSSION}

Over the past 60 years, a number of studies have aimed to establish the epidemiology of fractures within a geographically defined population. The classic study remains that sponsored by the Medical Research Council in the 1950s, estimating fracture incidence in Dundee and Oxford. ${ }^{3}$ Other examples include analyses of fracture incidence in older adults across Europe and in an American population, defined by insurance provision. ${ }^{12} 13$ The epidemiology of specific fracture types within populations has also been extensively studied. Examples include studies of foot and ankle fractures among elderly white women and the epidemiology of hand fractures. ${ }^{14}{ }^{15}$ In addition, fracture epidemiology has been described within populations with chronic disease, for example, patients with Crohn's disease. ${ }^{16}$ The present study is, however, the first to examine the incidence of fractures at any site, among people of all ages, in a sample designed to be representative of the general population, not just those who have sought medical care. It is known that minor fractures tend to be excluded from emergency department surveillance systems, ${ }^{17}$ whereas this self-report survey appears to capture them. In addition, this study estimates the lifetime prevalence of fractures within the population.

We found a higher overall fracture incidence (individuals experiencing one or more fractures in the past year) than had been estimated in previous studies (table 4).

In most of the studies cited, fracture occurrence was equated with patients with fractures presenting to hospital, typically the emergency department or fracture clinic. The denominator was usually taken as the catchment area served by that same hospital. In some papers, incident fractures were identified by retrospective analysis of general practitioner (primary care) case records. ${ }^{6}$ Each of these methods of fracture identification (case ascertainment) is likely to underestimate the number of 
Table 4 Selected United Kingdom studies examining fracture incidence

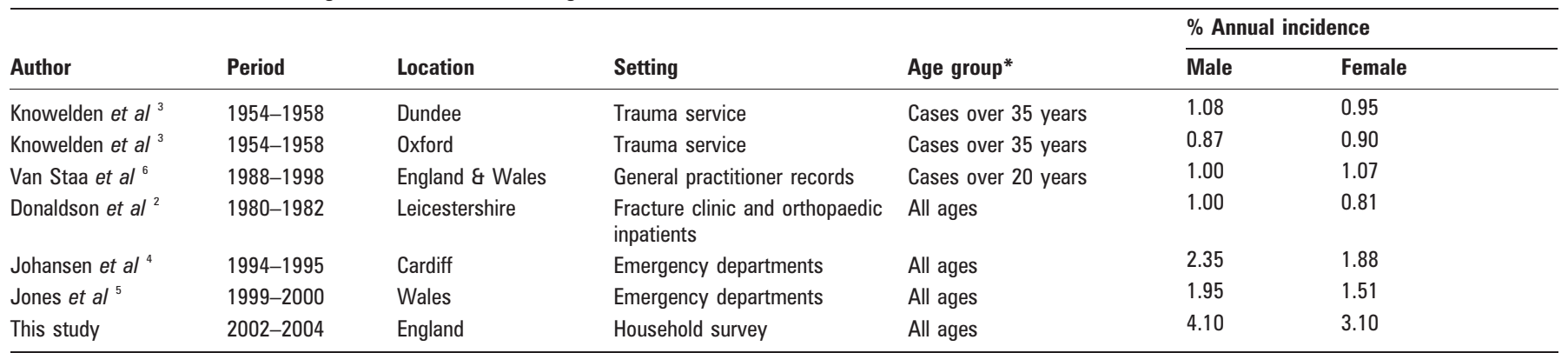

*Comparison between studies is limited by the different age groups included therein.

fractures occurring within a population on account of the factors outlined in Box 1 and Box 2.

Furthermore, a hospital's catchment population is not a reliable denominator for descriptive epidemiological study, as there may be geographical overlap between hospital providers, changes over time in referral behaviour or seasonal variation in the size of a population.
The present study, a household survey, avoids most of these difficulties. Numerator and denominator are established through a process involving the face-to-face questioning of a representative sample of individuals living in private households, randomly selected from the national Postcode Address File. The location or type of service in which any fracture was treated is immaterial. It should be noted that residents of
Figure 4 Age-standardised annual fracture incidence and lifetime fracture prevalence ratios by minority ethnic group compared with the general population, all ages, 2004. (A) Incidence. (B) Prevalence. $\mathrm{Cl}$, Confidence interval.

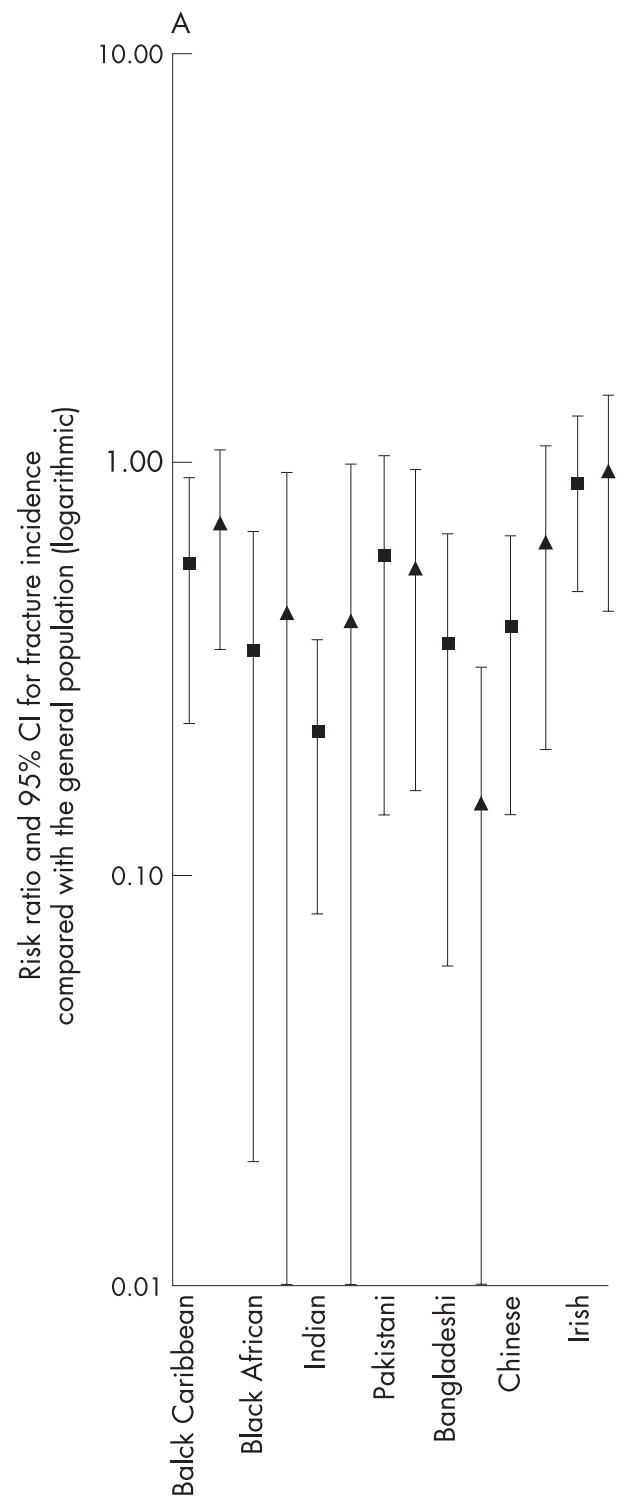

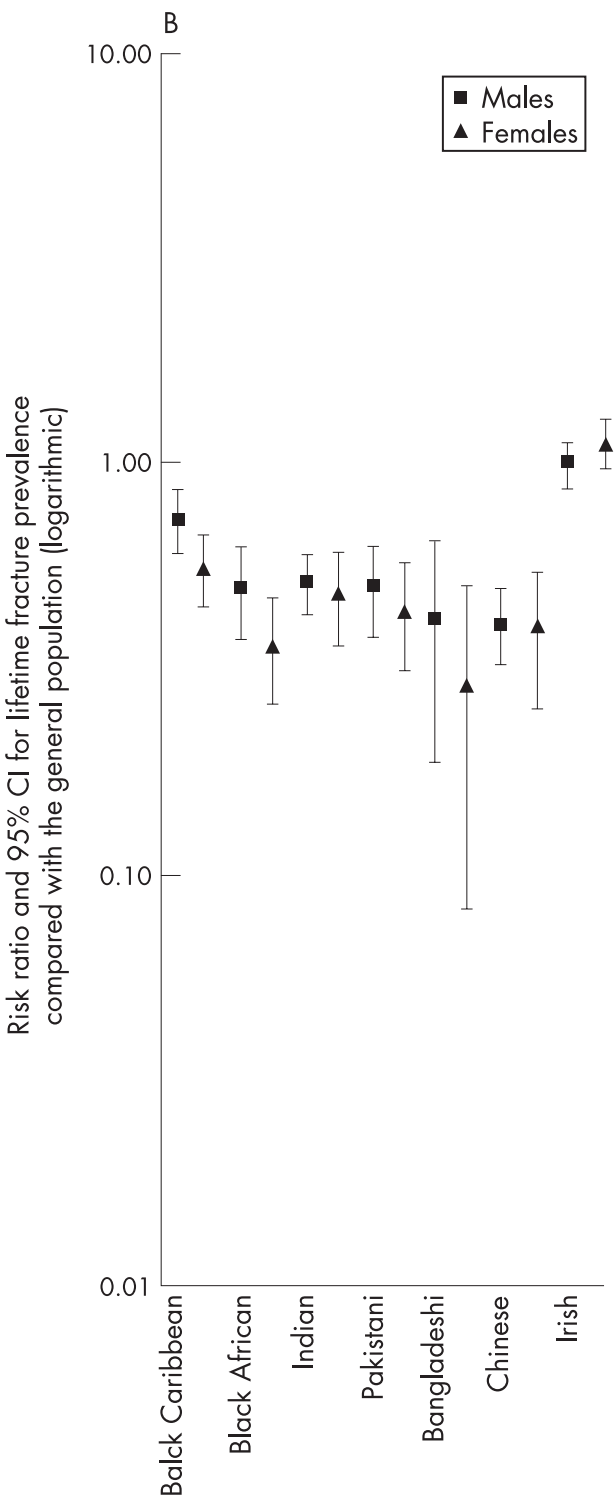




\section{What is known on this subject}

- The public health burden of fractures has been estimated by assessing the number of patients interacting with formal healthcare settings

- Reliable estimates of the lifetime fracture prevalence for the United Kingdom are not available

- Fracture incidence varies by age, occupation and sex, with a reversal in the male to female ratio between young adults and older adults

- Reliable comparative data on fracture incidence in non-white populations are not available

residential and nursing homes, potentially at altered risk of fracture, are not included in the survey.

There are, however, several features of self-report studies (in which retrospective data are gathered) that may lead to error and an overestimation of fracture incidence, including:

- inadvertent extension of the reference period by respondents (for example a fracture occurring 14 months ago is counted as being "within the past year')—so-called "telescoping";

- errors in case ascertainment (for example, "probable" fractures may be included in addition to definitive, X-rayconfirmed, fractures); and

- recall bias (for example, attributing soft tissue injury to fracture).

It is difficult to know the degree to which errors of case ascertainment might have erroneously elevated the calculated incidence rates. In one study examining the incidence of fractures in a female population with osteoporosis, the impact of these types of error was small, with $11 \%$ of self-reported fractures being false positives (negative radiographs) and a total of $20 \%$ being impossible to verify. ${ }^{18}$ Other work, however, implies that self-report studies might actually underestimate the incidence of fractures, particularly vertebral fractures. For example, one study found vertebral fractures in $22.8 \%$ of ambulant elderly women in France, many of whom were asymptomatic and unaware of their fractures. ${ }^{19}$ In our study, fractures are presented as reported by the study population and it is likely that asymptomatic non-traumatic fractures (notably vertebral fractures) are underreported.

In addition to the overall fracture incidence rates, data from this study yield important information about the distribution of fractures within the population. Many of the findings confirm the results of other studies:

- the near exponential rise in the number of hip fractures with age (presented as fig w1 in the online appendix);

- the bimodal distribution of fractures of the radius and ulna occurring in children and the elderly (presented as fig $w 1$ in the online appendix);

- the higher incidence of fracture in males from mid-childhood to early middle age; and

- the marked reversal in the male to female fracture incidence ratio in older adults and the elderly, likely to represent the impact of the menopause on bone health and stability.

The differing fracture incidence by social class found in this study lends weight to the findings of a 2004 analysis examining fracture incidence in Wales by Townsend deprivation score, ${ }^{5}$ and an examination of paediatric fractures by deprivation in Glasgow. ${ }^{20}$ The first of those studies showed that the increased rate of fracture in more deprived populations was caused entirely by a marked excess among young males. The reasons

\section{What this study adds}

- When obtained by self-reporting in a representative national community sample, the incidence of fractures is more than double previous estimates, at $3.6 \%$

- One in two middle-aged men and two in five women aged 75 years had experienced a fracture in their lifetime

- The reversal in the male to female ratio between young adults and older adults is confirmed, occurring across most fracture sites, and is likely to reflect postmenopausal bone density loss

- Consistently lower rates of fractures were found in the nonwhite population

for the trend seen by occupational group in this study are likely to be complex. In addition to the increased opportunity for injury afforded by manual occupations, occupational group, or social class, also serves as a surrogate marker for behaviour away from the workplace. Some behaviour traits may be associated with fractures: participation in sport, motorcycling and other high-risk activities, and certain patterns of alcohol use. Other studies have, however, shown no overall variation in the childhood fracture rate by deprivation, with high-risk sporting pursuits among the affluent counterbalancing any excess fractures in deprived communities. ${ }^{21}$

This study also provides a fresh insight into the relationship between ethnicity and fractures. Data from the general population describe significantly lower rates of fracture among children and young adults from non-white populations. These differences may be explained by reduced participation in highrisk activities (such as physical contact and winter sports). ${ }^{22} \mathrm{~A}$ trend towards a reduction in fracture incidence is also apparent in the older age groups, a feature that could perhaps be explained by virtue of differences in bone mineral density, or through increased social support and a reduced tendency to fall. ${ }^{23}$ In some Far Eastern populations, hip fracture is relatively uncommon, putatively on account of improved muscle mass and distribution (as a result of frequent squatting and floor sitting) lending additional stability to the hip joint. ${ }^{24}$ Such habits, and the apparent health benefit, may be retained after migration. The magnitude of the effect of ethnicity is made most powerfully by the separate analysis of data from HSE 2004. Age-standardised fracture prevalence is observed to be approximately half that seen in the general population in all ethnic groups examined and across both sexes, with the exception of the Irish group and black Caribbean males.

Other important information has also been gathered for the first time on the lifetime prevalence of fractures in the English population. For example, fracture prevalence continues to increase for women as they age, as one might expect. For men, however, there is a significant decline in lifetime prevalence after a peak prevalence in the 35-54-year-old age group. Possible explanations for this decline in lifetime prevalence with age are intriguing:

- perhaps many of the fractures that occur in elderly men befall individuals who have had previous fractures and spare those with no such history (as suggested by Van Staa and colleagues);

- perhaps there is a "healthy survivor" effect with some of those men sustaining fractures in their younger years not surviving to old age, ${ }^{25}$

- perhaps older men recall previous fractures less accurately, particularly as they tend to have occurred in childhood or 
early adulthood, requiring an extended period of recollection; or

- perhaps the behaviour and experience of young and middleaged men currently puts them at a genuinely heightened risk of fractures compared with the cohort that they follow.

\section{CONCLUSIONS}

This study demonstrates that the overall incidence of fractures is likely to be higher than previously thought and reaffirms that the burden placed on health and social services by fractures is likely to be important. For the first time, the lifetime prevalence of fractures in England has been estimated through a self-report study. In addition, the study maps out the epidemiology of fractures within the population, revealing or confirming striking variations by age, sex, social class and ethnicity. In particular, the data suggest that fractures occur very much less frequently among the non-white population of England. Understanding these factors will be important in designing strategies to minimise the incidence of fractures and thus reduce the burden that they impose on individuals and society.

Funding: The Health Survey for England (HSE) is funded by the Department of Health, England.

Competing interests: None.

Guarantor: j.mindell@ucl.ac.uk

Contributors: Originator of research: LJD; data collection: staff of the Joint Health Surveys Unit of NatCen and UCL; planning of analyses: all authors and B Sweeney; data analyses: SS; interpretation of results: all authors; first draft of manuscript: IPR; revisions to drafts: all authors.

\section{REFERENCES}

1. Parrott S. The economic cost of hip fracture in the UK. A paper commissioned by the Department of Trade and Industry. York: Centre for Health Economics, University of York, 2000.

2. Donaldson LJ, Cook A, Thomson RG. Incidence of fractures in a geographically defined population. J Epidemiol Community Health 1990;44:241-5.

3. Knowelden J, Buhr AJ, Dunbar 0 . Incidence of fractures in persons over 35 years of age. Br J Prev Soc Med 1964;18:130-41.

4. Johansen A, Evans RJ, Stone MD, et al. Fracture incidence in England and Wales: a study based on the population of Cardiff. Injury 1997;28:655-60.
5. Jones S, Johansen A, Brennan J, et al. The effect of socioeconomic deprivation on fracture incidence in the United Kingdom. Osteoporos Int 2004;15:520-4.

6. Van Staa T, Leufkens $H$, Cooper C. Does a fracture at one site predict later fractures at other sites? A British cohort study. Osteoporos Int 2001;13:624-9.

7. Gabbe BJ, Finch $\mathrm{CF}$, Bennell $\mathrm{KL}$, et al. How valid is a self-reported 12 month sports injury history? Br J Sports Med 2003;37:545-7.

8. Sproston K, Primatesta P, eds. Health survey for England 2002, vol. 3. Methodology and documentation. London: The Stationery Office, 2003.

9. Sproston K, Primatesta P, eds. Health survey for England 2003, vol. 3. Methodology and documentation. London: The Stationery Office, 2004.

10. Sproston K, Mindell J, eds. Health survey for England 2004, vol. 2. Methodology and documentation. London: The Information Centre, 2006.

11. UK Census 2001, Crown, London. http://www.statistics.gov.uk/census2001 (accessed 28 Feb 2007).

12. Ismail AA, Pye SR, Cockerill WC, et al. Incidence of limb fracture across Europe: results from the European Prospective Osteoporosis Study (EPOS). Osteoporos Int 2002;13:565-71.

13. Brinker MR, O'Connor DP. The incidence of fractures and dislocations referred for orthopaedic services in a capitated population. J Bone Joint Surg Am 2004;86A:290-7.

14. Hasselman CT, Vogt MT, Stone KL, et al. Foot and ankle fractures in elderly white women: incidence and risk factors. J Bone Joint Surg Am 2003;85-A:820-4.

15. Van Onselen EB, Karim RB, Hage JJ, et al. Prevalence and distribution of hand fractures. J Hand Surg 2003;28:491-5.

16. Klaus J, Armbrecht G, Steinkamp M, et al. High prevalence of osteoporotic vertebral fractures in patients with Crohn's disease. Gut 2002;51:654-8.

17. Lyons RA, Polinder S, Larsen CF, et al. Methodological issues in comparing injury incidence across countries. Int J Inj Contr Saf Promot 2006;13:63-70.

18. Nevitt M, Cummings S, Browner W, et al. The accuracy of self-report of fractures in elderly women: evidence form a prospective study. Am J Epidemiol 1992;5:490-9.

19. Grados F, Marcelli C, Dargent-Molina P, et al. Prevalence of vertebral fractures in French women older than 75 years from the EPIDOS study. Bone 2004;34:362-7.

20. Stark AD, Bennet GC, Stone DH, et al. Association between childhood fractures and poverty: population based study. BMJ 2002;324:457.

21. Lyons RA, Delahunty AM, Heaven $M$, et al. Incidence of childhood fractures in affluent and deprived areas. BMJ 2000;320:149.

22. Stamatakis E. Physical activity. In: Sproston K, Midell J, eds. Health survey for England 2004. London: The Stationary Office, 2006.

23. Tracy JK, Meyer WA, Grigoryan M, et al. Racial differences in the prevalence of vertebral fractures in older men: the Baltimore Men's Osteoporosis Study. Osteoporos Int 2006;17:99-104.

24. Mayhew PM, Thomas CD, Clement JG, et al. Relation between age, femoral neck cortical stability and hip fracture risk. Lancet 2005;366:98-9.

25. Cameron CM, Purdie DM, Kliewer EV, et al. Long-term mortality following trauma: 10 year follow-up in a population-based sample of injured adults. J Trauma 2005;59:639-46. 